\title{
Controlled Environments for Production of Value-added Food Crops with High Phytochemical Concentrations: Lycopene in Tomato as an Example
}

\author{
Chieri Kubota ${ }^{1}$ \\ Department of Plant Sciences, The University of Arizona, Tucson, AZ 85721 \\ Cynthia A. Thomson \\ Department of Nutritional Sciences, The University of Arizona, Tucson, AZ 85721 \\ Min Wu and Jamal Javanmardi \\ Department of Plant Sciences, The University of Arizona, Tucson, AZ 85721
}

\begin{abstract}
Additional index words. antioxidant, electrical conductivity, greenhouse, Lycopersicon esculentum, salinity
Summary. Plants produce various phytochemicals that are of nutritional and medicinal value to humans. Phytochemicals having antioxidant capacity are drawing increased interest from consumers. Population studies among Americans have consistently demonstrated inadequate consumption of fruit and vegetables. Improving intake of fruit and vegetables has been a major public health effort for many years with minimal success. Given this, it seems opportunistic to consider other approaches to enhance the nutritional quality of the American diet. One plausible approach is the development of fresh produce containing a greater concentration of phytochemicals known to improve health, thus while consuming fewer servings of produce, Americans would still have significant exposure to health-promoting food constituents. Controlled environments provide a unique opportunity to modify the concentrations of selected phytochemicals in fruit and vegetables, yet practical information is limited regarding methods effective in optimizing antioxidant capacity. Our research at the University of Arizona Controlled Environment Agriculture Program has shown that application of moderate salt stress to tomato plants can enhance lycopene and potentially other antioxidant concentrations in fruit. The increase in lycopene in response to salt stress in the tomato fruit was shown to be cultivar specific, varying from $34 \%$ to $85 \%$. Although the specific biological mechanisms involved in increasing fruit lycopene deposition has not been clearly elucidated, evidence suggests that increasing antioxidant concentrations is a primary physiological response of the plant to the salt stress. Another experiment showed that low temperature during postharvest increased antioxidant capacity of tomato fruit while it maintained the lycopene concentration. More detailed study in this area is needed including accumulation of antioxidant phytochemicals as affected by environmental conditions during the cultivation and the postharvest.
\end{abstract}

\section{BACKGROUND AND OPPORTUNITY OF VALUE ADDED GREENHOUSE CROP PRODUCTION}

Controlled environment agriculture (or protected cultivation) has been a significant production mode for fruit and vegetables in many countries. However, in the United States, production of fruit and vegetables is traditionally dependent on the field cultivation located in multiple climate zones. Combined with imports from neighboring countries, domestic field produce has satisfied the year round demand, and as a consequence, use of controlled environment technologies such as greenhouse in production of fruit and vegetables was almost negligible up to early 1990 s. Tomato has been the major crop produced in the U.S. greenhouses followed by cucumber, lettuce and peppers. Of the fresh tomato production in the U.S. in 2003, greenhouse tomato production reportedly accounted for only $9 \%$ of total production $(159,664$ and 1,594,241 t from greenhouse and field, respectively) (Cook and Calvin, 2005). However, the percentage

CEAC Paper\#D-579473-18-05. This paper includes results out of collaborative research funded by The University of Arizona Bio5 Institute. Acknowledgements are also extended to Controlled Environment Agriculture Program and EuroFresh Farms for the technical and financial support.

${ }^{1}$ To whom reprints should be addressed; e-mail ckubota@ag.arizona.edu. of greenhouse tomato available in U.S. retail markets has increased dramatically during the past decade and now accounts for $37 \%$ of the weekly quantity of tomatoes sold in the average U.S. supermarket in 2003 (Cook and Calvin, 2005), where this quantity included produce imported from Mexico and Canada. This suggests that greenhouse tomatoes are preferred in retail sales likely due to the consistent supply and generally higher quality than field grown tomatoes. This trend seems driving neighboring countries more into greenhouse production. Canada produced $89 \%$ of fresh tomato in the form of greenhouse tomato (Cook and Calvin, 2005). In Mexico, the total area of greenhouse used for production of vegetables is increasing rapidly, reportedly as high as $30 \%$ increase annually (Steta, 2004). Due to the competition, U.S. greenhouse growers are shifting toward high value cultivars in order to compete with Canadian and Mexican growers.

In addition, trend surveys have suggested over the past decade that about $30 \%$ of Americans have a significant interest in diet and nutrition to improve their health and are actively making food choices to improve health (American Diabetes Association, 2002). Another $30 \%$ are interested, but may either lack the knowledge or express concern that a healthy diet may be too inconvenient or time consuming. To satisfy these consumer groups and increase produce sales, marketers are increasingly labeling produce with nutritional information, despite no regulations requiring they do so. Specifically, we noted that the tomato was being marketed for its high lycopene/antioxidant content as well as the fact that production of selected tomates was pesticide-free/organic. This marketing strategy, to provide added value to the produce appears to be effective in increasing sales as well as intake.

The human body uses various antioxidants for defense, some of which are dietary derived. The plant-based dietary antioxidants are believed to have an important role in the maintenance of human health because our endogenous antioxidants provide insufficient protection against the constant and unavoidable challenge of reactive oxygen species (ROS) (Benzie, 2003; Fridovich, 1998; Gracy et al., 1999). ROS are constantly produced and the production is enhanced by various environmental and biological factors. Generally, ROS induce oxidative damage to key biological sites such as DNA and the lipid membranes of cells, resulting in the accumulation of oxidative damage with age, which eventually contributes to the senescence and development of age-related disease (Benzie, 2003).

Plants produce various biologically active compounds that can promote antioxidation in the human body. Such compounds in fruit and vegetables include vitamin $C$, vitamin E, polyphenols, and carotenoids among others. The concentrations and profile of these components 
vary with cultivation practices and environmental conditions as well as genotypes (species and cultivars). For example, concentration of lycopene in tomatoes was reportedly altered by light quantity and quality (Alba et al., 2000; Dumas etal., 2003), air temperature (Baqar and Lee, 1978) and level of salinity in the nutrient solution (De Pascale et al., 2001).

One carotenoid with demonstrable antioxidant capacity is lycopene. In the human body lycopene deposition has been shown in the adrenals, liver, lung, testes, colon, skin and prostate. Lycopene is among the most efficient singlet oxygen quenchers in the human diet. Lycopene is thought to play a primary role in the prevention of chronic diseases including cancers and cardiovascular disease, where accumulation of reactive nitrogen species results in an accumulation of oxidative damage.

It also has been well established that diets high in fruit and vegetables, including tomatoes rich in lycopene, can reduce disease incidence. In fact, diet-based epidemiological studies, from case-control to intervention trials, have demonstrated that diets rich in fruit and vegetables can protect against cardiovascular disease, cancer, diabetes, rheumatoid arthritis, hypertension, and obesity (Steinmetz and Potter. 1996). High intake of fruit and vegetables, particularly those low in caloric content and sufficient in fiber, such as tomatoes, can also increase satiety and contribute to an overall reduced energy-density diet (Howarth et al., 2001). Although limited data are available to describe the health benefits of tomatoes specifically, growing evidence indicates that lycopene, the key antioxidant carotenoid in tomato, may have a unique role in overall health, particularly when it comes to the prevention of chronic disease. More importantly, dietary intake of tomatoes and processed tomato products has been inversely associated with risk of several cancers in case-control and prospective cohort studies (Giovannucci, 1999).

Measurement of dietary intake within the American population has repeatedly demonstrated an inadequate consumption of fruit and vegetables (Centers for Disease Control and Prevention NHANES survey data, 2005; USDA FSRG, 2002). Increasing daily intake of fruit and vegetables has been a major public health focus for many years with minimal success. The 5-A-Day for Better Health program is among the largest of these educational programs and involves the participation of numerous public and private organizations. The 5-A-Day program was been funded since 1991 by the U.S. government and primary administration lies with The Produce for Better Health Foundation. According to a 2003 evaluation of the 5-A-Day program, mean fruit and vegetable consumption among U.S. adults, was estimated at 4.1 servings a day and only $31 \%$ of the adult population consumed $>5$ servings a day, while only $10 \%$ achieved the new recommendations of 7 servings a day for women and 9 servings a day for men (National Cancer Institute, 2002). Although there has been a slow and steady increase in consumption over time according to NCI data (1989-91 and 1994-96) (http://www.cancercontrol.cancer. gov/5ad exec.html) and improving diet is a long term effort, it seems implausible that new recommendations of further increased daily consumption of fruit and vegetables among various age, gender and race groups will be met any time in the near future.

Given a general resistance by Americans to increase daily fruit and vegetable intake to recommended daily consumption levels, it seems opportunistic to develop fresh produce containing a greater concentration of phytochemicals to improve health. As an example, we have focused our efforts on increasing lycopene concentrations in tomato fruit.

\section{PRODUCTION OF HIGH LYCOPENE TOMATO UNDER CONTROLLED ENVIRONMENTS}

Cultivar and nutrient solution electrical conductivities as factors affecting lycopene concentration in the fruit. Tomatoes grown under water stress generally develop a richer fruit color in addition to an enriched flavor. The recent study at the Controlled Environment Agriculture Program, The University of Arizona, showed that lycopene concentration of tomato fruit was enhanced significantly without reducing the total fruit yield by growing plants under a moderate salt stress provided by high salt concentration in the nutrient solution $(\mathrm{Wu}$ et al., 2004). The fruit quality when plants were grown hydroponically using a nutrient solution with higher electrical conductivity (EC) was significantly greater than those grown under the standard conditions (low EC) (Wu et al., 2004). Most importantly this higher EC growing condition resulted in significant increases in lycopene concentration. The electrical conduc- tivity of the nutrient solution was 2.4 (low EC) or $4.5 \mathrm{dS} \cdot \mathrm{m}^{-1}$ (high EC). The increase in total lycopene in the fruit was shown to be cultivar specific, varying from $34 \%$ to $85 \%$ (Fig. 1). The highest lycopene concentration was observed for the cultivar 'Quest' $\left(74 \mathrm{mg} \cdot \mathrm{kg}^{-1}\right.$ of fresh fruit or $10 \mathrm{mg}$ per $130 \mathrm{~g}$ serving) grown under high EC and the greatest difference between high EC and low EC was observed for the cultivar 'Mariachi' ( $85 \%$ increment). Enhanced lycopene concentration was also observed by applying water stress caused by limited irrigation (Matsuzoe et al., 1998; Zushi and Matsuzoe, 1998). This indicates that, while the high $\mathrm{EC}$ was achieved by adding $\mathrm{NaCl}$ to the nutrient solution in the experiment described above, similar enhancement of lycopene may be achieved by increasing the strength of the nutrient concentration, rather than adding $\mathrm{NaCl}$ to the solution.

Tomato has six ripening stages characterized with color development, which include green, breakers, turning, pink, light red and red(USDAagricultural marketing service fruit and vegetable division, 1975). The ripening of tomato fruit is accompanied by the chlorophyll degradation and lycopene synthesis, as chloroplasts are converted into chromoplasts (Rhodes, 1980; Fraser et al., 1994). Under high EC $\left(4.5 \mathrm{dS} \cdot \mathrm{m}^{-1}\right)$, the lycopene started accumulating earlier than did under low EC $\left(2.4 \mathrm{dS} \cdot \mathrm{m}^{-1}\right)$ for both cultivars of 'Mariachi' and 'Durinta'(Fig. 2). For 'Mariachi', lycopene concentration in tomato fruit was observed at a level of $12.4 \mathrm{mg} \cdot \mathrm{kg}^{-1}$ fresh weight for plants grown under high EC at 6 weeks after anthesis, whereas no lycopene was detected for fruit under low EC at the same time. Lycopene was detected for 'Durinta' fruit grown both under

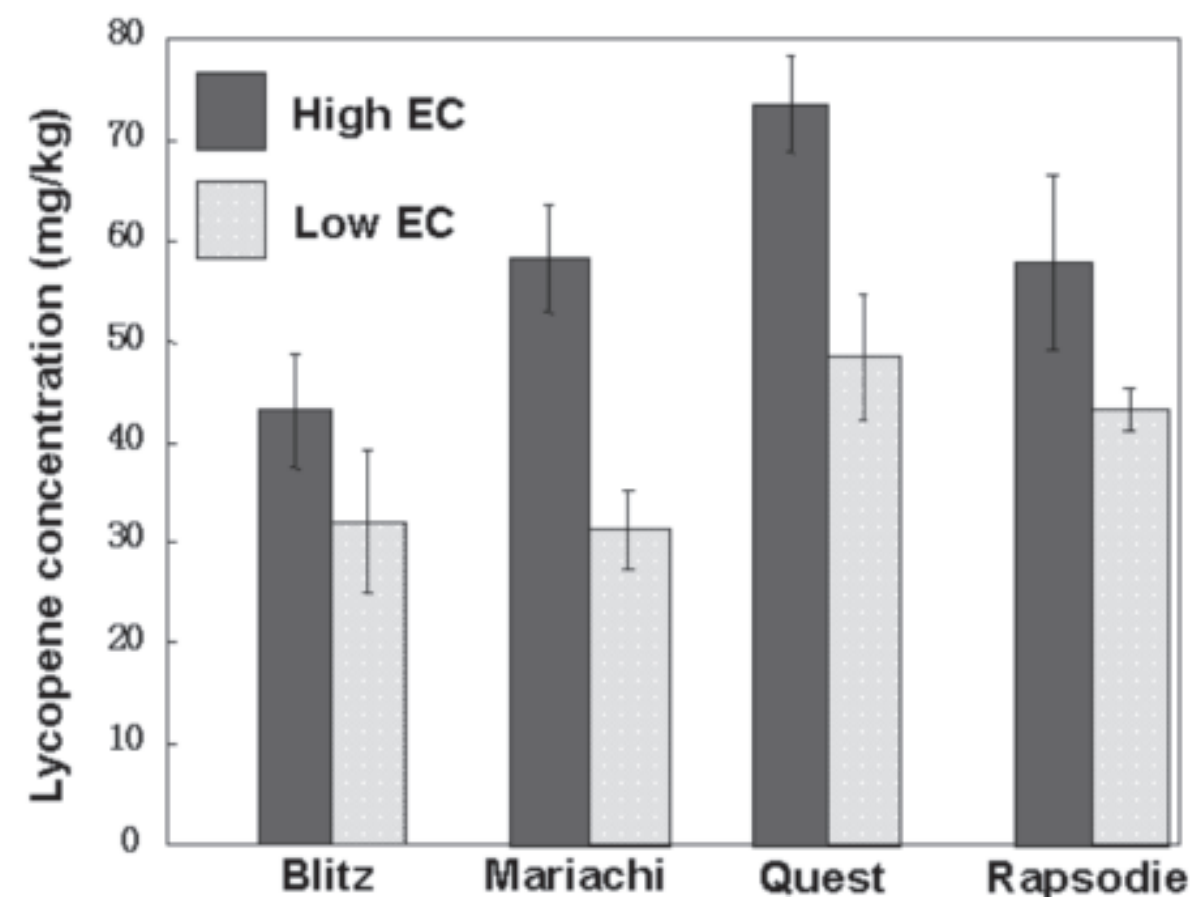

Fig. 1. Lycopene concentration of vine-ripe tomato fruit as affected by EC (electrical conductivity) and cultivar (Wu et al., 2004). Under high EC $\left(4.5 \mathrm{dS} \cdot \mathrm{m}^{-1}\right)$, fruit lycopene concentration increased significantly in all four cultivars ('Blitz', 'Mariachi', 'Quest', and 'Rapsodie') compared to those under low $\mathrm{EC}\left(2.4 \mathrm{dS} \cdot \mathrm{m}^{-1}\right)$. 

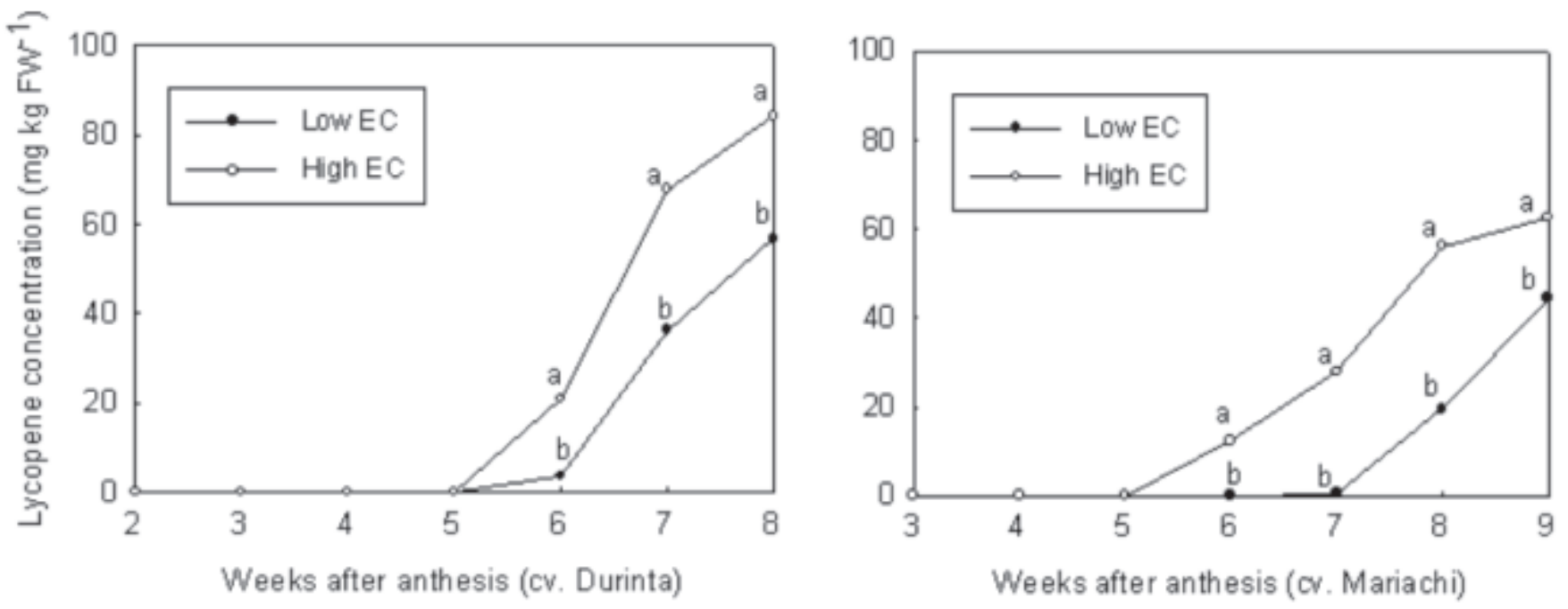

Fig. 2. Lycopene development over time (weeks after anthesis) in tomatoes as affected by nutrient solution EC [electrical conductivity (Wu et al., unpublished data)]. Under high EC $\left(4.5 \mathrm{dS} \cdot \mathrm{m}^{-1}\right)$, lycopene started accumulating earlier than did under low EC $\left(2.4 \mathrm{dS} \cdot \mathrm{m}^{-1}\right)$. Two cultivars—a beefsteak type 'Mariachi' and a cluster type 'Durinta' were tested. Different letters indicate the significant difference at each observation week by $t$ test at $P<0.05$.

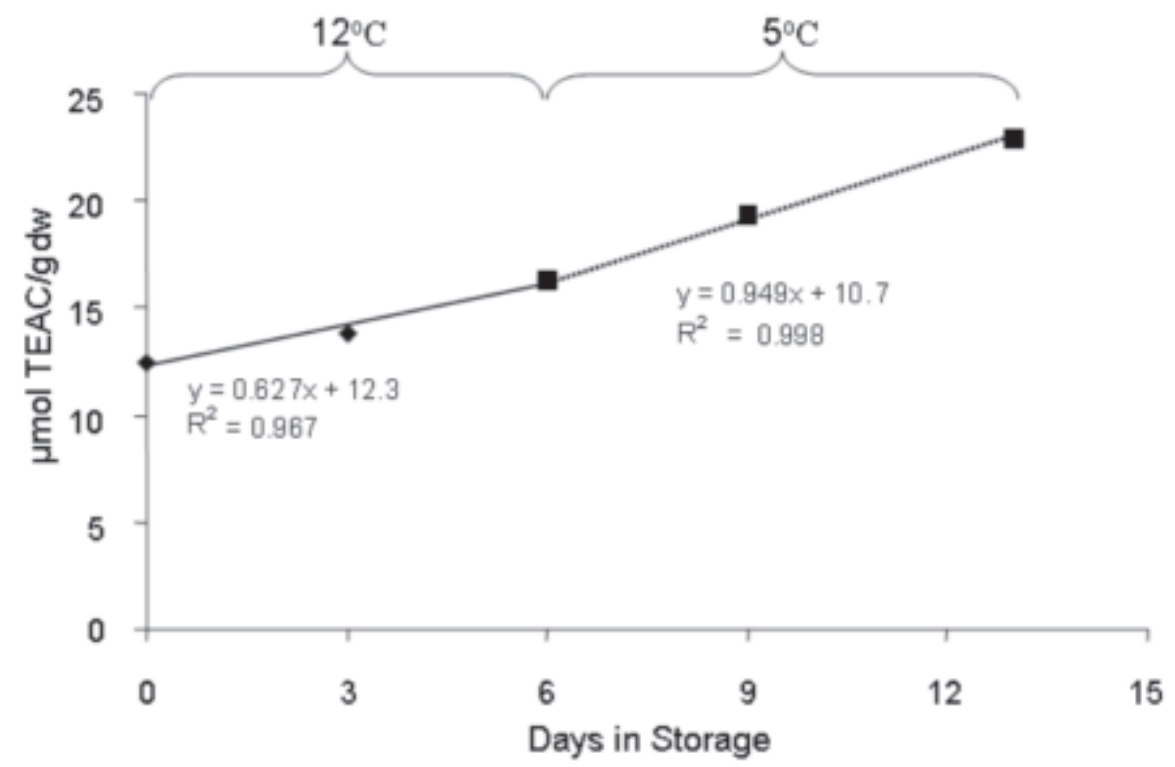

Fig. 3. Trolox equivalent antioxidant activity (TEAC) of tomatoes as affected by storage temperature conditions (Javanmardi and Kubota, unpublished data).

high and low EC at 6 weeks after anthesis; however, lycopene concentration was much higher in fruit under high EC $\left(20.8 \mathrm{mg} \cdot \mathrm{kg}^{-1}\right.$ fresh weight) than those under low EC (3.6 $\mathrm{mg} \cdot \mathrm{kg}^{-1}$ fresh weight).

Mechanisms of lycopene enhancement under water and nutritional stress. Although the exact biological mechanisms that contribute to the enhancement of lycopene concentration under high EC stress are not known, evidence suggests that ethylene synthesis triggered by water and salt stress could be central to the increase in lycopene deposition within the flesh of the tomatoes. The fruit ripening process begins with an increase in respiration and ethylene $\left(\mathrm{C}_{2} \mathrm{H}_{4}\right)$ synthesis. Application of ethylene is known to trigger ripening and is often used to enhance ripening of green-harvested tomatoes from the field. Development of red color (primarily contributed to the presence of lycopene) begins after this initial increase in ethylene. The lycopene concentration increases rapidly during this maturation process. Under stressed conditions with high $\mathrm{Na}$ and $\mathrm{Cl}$, and thereby high EC nutrient solution, our preliminary results showed that the tomatoes developed from the green stage, where no red pigments were visually seen on the tomato surface to the breaker stage, where $<10 \%$ of surface has red pigment in a significantly shorter period of time than fruit that developed under conventional nonstressed conditions (Wu et al., unpublished). Salinity is known to induce ethylene emission across several tomato cultivars (Mizrahi, 1982). Botella et al. (2000) has shown that irrigation of tomato plants with 40 to $60 \mathrm{~mm} \mathrm{NaCl}$ increases red color, ethylene production and total ACC (1aminocyclopropane-1-carboxylic acid). This suggests that ethylene production induced by saline stress enhanced the concentration of lycopene in the tomatoes. Thus, under water and salt stress, tomatoes mature earlier and accumulates more lycopene during the time before harvest. The altered water balance secondary to reduced water flow to the fruit under high EC conditions appears to contribute even further to the deposition of lycopene on a fresh weight basis. However, excessive stress to the plants often reduces the overall yield. Preliminary results from our greenhouse tomato production experiments suggest that increasing EC from 2.5 to $4.5 \mathrm{dS} \cdot \mathrm{m}^{-1}$ could sustain yield but further increase of EC should be avoided as it would reduce the yield ( $\mathrm{Wu}$ et al., 2004).

Storage effects on lycopene and overall antioxidant capacity. Fruit and vegetables are subject to a variety of conditions after harvest that can alter nutrient content. Postharvest technologies have been developed to maximize the quality and to minimize the undesirable changes in fruit and vegetables during post harvest handling. The biology and compositional changes that occur in harvested fruit and vegetables are well known, yet there is a paucity of information regarding the overall change in the antioxidant capacity of harvested fruit and vegetables under postharvest conditions. According to our recent study, tomatoes at a red ripe stage demonstrated increased trolox equivalent antioxidant capacity (TEAC) under low temperature storage $\left(12{ }^{\circ} \mathrm{C}\right.$ for the first 6 $\mathrm{d}$ and $5{ }^{\circ} \mathrm{C}$ for the following $7 \mathrm{~d}$ ) (Javanmardi and Kubota, unpublished data) (Fig. 3). At 13 d of postharvest at $12 / 5^{\circ} \mathrm{C}$, tomatoes exhibited almost double the TEAC as compared with the level before storage. Tomatoes stored at a room temperature $\left(25^{\circ} \mathrm{C}\right)$ did not show a significant change in TEAC, although lycopene concentration increased over time (data not shown). These results need to be re-examined to include the quantification of all major antioxidants of the tomatoes (phenols, vitamin C, and lycopene). Modulation and control of total antioxidant capacity as affected by shipping, 
handling and storage conditions after harvest is an important area of research for postharvest controlled environment technology.

\section{CONCLUSIONS}

Traditionally, manipulation of plant growth and development has been a major focus area of research in controlled environment plant physiology. Growing interest in nutritional value of horticulture food crops has promoted the interdisciplinary research of controlled environments to manipulate target compounds in plants such as phytochemicals and antioxidants of fruit and vegetables by controlling environmental conditions. Further research with collaborations in postharvest physiology, nutritional science, biochemistry, and molecular biology in addition to controlled environment plant physiology will help to develop technologies and to elucidate the detailed mechanisms of manipulating phytochemicals and antioxidants by controlled environments.

\section{Literature Cited}

Alba, R., M.M. Cordonnier-Pratt, and L.H. Pratt. 2000. Fruit-localized phytochromes regulate lycopene accumulation independently of ethylene production in tomato. Plant Physiol. 123:363-370.

American Diet Association. 2002. Nutrition \& you: Trends 2002. Final report. 14 July 2005. http://www.eatright.org/Public/Media/PublicMedia 10240.cfm.

Baqar, M.R. and T.H. Lee. 1978. Interaction ofCPTA and high temperature on carotenoid systhesis in tomato fruit. Z. Planzenphysiol. 88:431-435.
Benzie, I.F.F. 2003. Evolution of dietary antioxidants. Comparative Biochem. Physiol. Part A 136:113-126.

Botella, M.A., F. Del Amor, A. Amoros, M. Serrano, V. Martinez, and A. Cerda. 2000. Polyamine, ethylene and ohter physico-chemical parameters in tomato (Lycopersicon esculentum) fruit as affected by salinity. Physiol. Planta. 109:428-439.

Centers for Disease Control and Prevention. 2005. National health and nutrition examination survey. 14 July 2005. http://www.cdc.gov/nchs/nhanes. $\mathrm{htm}$.

Cook, R. and L. Calvin. 2005. Greenhouse tomatoes change the dynamics of the North American Fresh Tomato Industry. USDA Economic Research Report No. 214 July 2005. www.ers.usda.gov.

De Pascale, S., A. Maggio, V.Fogliano, P.Ambrosino, and A. Ritieni. 2001. Irrigation with saline water improves carotenoids content and antioxidant activity of tomato. J. Hort. Sci. Biotechnol. 76(4):447-453.

Dumas, Y, M. Dadomo, G. Di Lucca, and P. Grolier. 2003. Effects of environmental factors and agricultural techniques on antioxidant content of tomatoes. J. Sci. Food Agr. 83:369-382.

Fraser, P.D., M.R. Truesdale, C.R. Bird, W. Schuch, and P.M. Bramley. 1994. Carotenoid biosynthesis during tomato fruit development. Plant Physiol. 105:405-413

Fridovich, I. 1998. Oxygen toxicity: a radical explanation. J. Expt. Biol. 210:1203-1209.

Giovannucci, E. 1999. Tomatoes, tomato-based products, lycopene, and cancer: review of the epidemiologic literature. J. Natl. Cancer Inst. 91:317-331.

Gracy, R.W., J.M. Talent, Y. Kong, and C.C. Conrad. 1999. Reactive oxygen species: the unavoidable environmental insult? Mutation Res. 428:17-22.

Howarth, N.C., E. Saltzman, and S.B. Roberts.
2001. Dietary fiber and weight regulation. Nutr. Rev. 59:129-39.

Matsuzoe, N., K. Zushi, and T. Johjima. 1998 Effects of soil water deficit on coloring and carotene formation in fruit of red, pink and yellow type cherry tomatoes. J. Jpn. Soc. Hort. Sci. 67(4):600-606.

Mizrahi, Y. 1982. Effect of salinity on tomato fruit ripening. Plant Physiol. 69:966-970.

National Cancer Institute. 2002. NCI 5-A-Day Attitude and Behavioral Tracking. National Omnibus Survey Results. 15 June 2005. http://www.5aday. gov/pdf/2002Omnibus_Report.doc.

National Cancer Institute. 5-A-Day for Better Health Program Evaluation Report. 15 June 2005. http://www.cancercontrol.cancer.gov/5ad_exec. html.

Rhodes, M.J.C.1980. The maturation and ripening of fruit, p. 157-205. In: K.V. Thimann(ed.). Senescence in plants. CRC press, Boca Raton, Fla

Steinmetz, K.A. and J.D. Potter. 1996. Vegetables, fruit, and cancer prevention: a review. J. Amer. Diet Assoc. 96:1027-39.

Steta, M. 2004. Mexico as the new major player in the vegetable greenhouse industry. Acta Horticulturae. 259:31-36.

USDAFSRG. 2002. Products from the CSFII/DHKS 1994-96, 1998. 14 July 2005. http://www.barc. usda.gov/bhnrc/foodsurvey/Products.html.

USDA. 1975. United State standards for grade of fresh tomatoes. U.S. Dept. Agr., Mktg., Serv., Wash., D.C. PP10.

Wu, M., J.S. Buck, and C. Kubota. 2004. Effects of nutrient solution EC, plant microclimate and cultivars on fruit quality and yield of hydroponic tomatoes (Lycopersicon esculentum). Acta Horticulturae 659:541-547.

Zushi, K. and N. Matsuzoe. 1998. Effects of soil water deficit on vitamin $\mathrm{C}$, sugar, organic acid and carotene contents of large-fruited tomatoes. J. Jpn. Soc. Hort. Sci. 67:927-933. 